\title{
Assessment of the Innovative Potential of Alternative Energy in the Context of the Transition to the Circular Economy
}

\author{
Andrey Zaytsev ${ }^{1}$, Nikolay Dmitriev ${ }^{1}$, Dmitriy Rodionov$^{1}$, Tengiz Magradze $^{2}$ \\ ${ }_{1}^{1}$ Peter the Great St.Petersburg Polytechnic University, St.Petersburg, Polytechnicheskaya, 29, 195251, Russia \\ ${ }^{2}$ Georgian Technical University, 77, M. Kostava Street, Tbilisi 0171, Georgia
}

\begin{abstract}
The purpose of this article is to consider the innovative potential of alternative energy at the level of an economic entity in the context of increasing the global significance of the transition to the circular economy. The authors consider the conceptual provisions of the circular economy and the place of alternative energy in it, as well as justify the possibility of increasing the level of innovation through the implementation of "clean" energy development programs. As an assessment of the innovative potential of alternative energy at the level of an economic entity, the authors propose an integral model that takes into account the specified parameters of innovation. To adapt the idea, the authors chose the enterprise management level, since it is at this level that the greatest innovative activity which can affect the diffusion of "circular" innovations is manifested. The article proposes to analyze the economic entities who implement recycling for the further production of energy resources. For the parametric integral assessment, the weighting coefficients of the key performance indicators were set. The analysis of the number of companies revealed a strong correlation between the integral indicator of innovation potential and the level of circular energy efficiency.
\end{abstract}

Keywords: Alternative energy; Circular economy; Innovative potential; Innovative energy; Innovative development; Renewable energy

\section{Introduction}

The trends of the $21^{\text {st }}$ century are directly related to the extensive growth of energy resource consumption, primarily in industrial production, which consumes more than $80 \%$ of the world's energy output (Zhiltsov et al., 2020). However, this practice causes serious problems with the quality of the resources used as well as their impact on sustainable development. It is necessary to be critical of the dominant paradigm of science and technology, the vision of which does not always correspond to the maintenance of global sustainability (Azzopardi, 2017). Thus, sustainable development becomes the main direction of the strategic functioning of the macroeconomic space, the achievement of which is associated with the creation of an appropriate innovation potential (Bermejo, 2014).

Over the past two years, the global community has been discussing the threats to and opportunities for energy development in the context of the COVID-19 pandemic, as well as the emergence of new negative externalities that pose barriers to achieving global 
sustainable development. It is necessary to highlight the current problems, which include a sharp increase in household waste and other non-recyclable resources. Their use in the energy context has not yet been fully considered in the scientific and practical environments and is ignored in practice by many developing countries (Chen, 2020; Sarkodie and Owusu, 2020). At the same time, innovative development can give significant impetus to the formation of a circular economy and provide a comprehensive approach to the transformation of the ecological and economic space of the territories, creating conditions for reducing not only the volume of waste, but also the negative consequences of traditional energy. The functioning of innovative activities of the business sector based on the principles of sustainable development will lead to the creation of the necessary tools for eco-efficiency and methods of economic management aimed at solving the socioeconomic problems of our time in the long term (Witjes and Lozano, 2016).

From the authors' point of view, innovation potential is a significant indicator of economic activity, since it determines the availability of opportunities to modernize and create innovative infrastructure through the large-scale technological renewal of individual entities and entire sectors of the national economy (Rudskaia et al., 2017; Zaborovskaya et al., 2019). Alternative energy, as a high-tech industry, is able to create a sufficient level of innovation potential, and its focus on matching the closed-cycle economy will allow to extract additional energy efficiency from secondary raw materials waste (Murray et al., 2017; Chernysheva et al., 2019).

To date, the adaptive cycles of ecosystems have been facing serious challenges, which can only be overcome through innovative means. Circular models should take into account the energy needs of society, and therefore consider ways to obtain "clean" energy that does not create negative socio-environmental externalities for the state and society. Thus, the key goal of this article is to consider the innovative potential of alternative energy at the level of an economic entity in the context of the transition to the circular economy. To achieve this goal, the proposal is to determine the current innovative state of alternative energy; analyze the conceptual provisions of the circular economy; consider the place of alternative energy in circular models; and build a model for assessing the innovative potential of alternative energy enterprises. The solution of the set tasks will allow us to justify the growth of the level of innovation through the implementation of "clean" energy development programs and to identify the key determinants of the construction of the circular economic system.

\section{Methods}

This research is based on the analysis of interdisciplinary works and statistical data. The problems of sustainable development, circular economy, alternative energy, and innovative development are discussed. Based on the available research in these areas, it is possible to consider different points of view in the scientific community on the problem and to determine interdisciplinary ways to solve it.

In the process of analyzing the current state of this issue, three blocks were identified: the innovative component of alternative energy, the conceptual provisions of the circular economy, and the place of alternative energy in circular models.

\subsection{The Innovative Component of Alternative Energy}

Due to the growth of both industrial production and the global population, energy consumption around the world is increasing. In such conditions, there is also an extensive increase in energy waste, which has a negative impact on ecosystems and people's quality of life. For example, Bermejo (2014) notes that the search for alternative energy sources is 
an important step toward ensuring a sustainable future for all of humanity. Energy systems should be transformed under the current trends of the time, and the integration of renewable and other alternative energy sources into the existing infrastructure would allow us to synchronize environmental needs and the needs of overall development with other socially significant areas, as noted in the work of Azzopardi (2017). This is certainly promising, but it will not be possible to fully cover all the needs of humanity at the expense of alternative energy in the near future. At the same time, even a slight increase in its growth should be accompanied by the creation of innovative potential and the reduction of the negative consequences of human economic activity. It is possible to arrange the recombination of knowledge elements to improve the quality of innovation activities (Guan and Yan, 2016). Finding ways to create the innovative potential of alternative energy is associated with a number of difficulties, however, since the dynamics of the innovation space are characterized by a high level of uncertainty, which has been confirmed by many studies (e.g., Madureira, 2014; Schwarz, 2017; Doukas et al., 2018).

Uncertainty factors are extremely important in shaping the future trajectory of alternative energy development. At the moment, the structure of the world economy is undergoing significant changes due to the processes of globalization, the transition to a new technological order, and the requirements of sustainable development. These trends form a fundamentally new context for the global energy system (as noted in, e.g., Common and Stagl, 2005; Soderbaum, 2013; Bhattacharyya, 2019).

In the context of the expanded growth of innovation, new opportunities are opening up for alternative energy, primarily due to the ubiquitous spread of digitalization, which makes it possible to rationalize business processes and integrate disparate enterprises of the energy sector into single chains. The analysis of digital processes in the economy and their impact on economic growth is elaborated in the works of Elder-Vass (2016), Bataev (2018), and Vasetskaya and Gaevskaia (2019). The innovative component of alternative energy in this context is directly related to digital transformation. Knowledge-intensive production and the minimization of the negative impact of material and economic externalities open up a number of potential opportunities for consolidating the socio-environmental agenda at both the state and business levels, contributing to the spread of innovative capital between different-level entities (Mamrayeva et al., 2018). The socio-economic essence of this process is related to the qualitative improvement and updating of the existing technological base, which allows to improve the quality of life of the population as well as the environmental situation.

In the process of analyzing special reports (SR15, 2018; SRCCL, 2019) prepared for the United Nations, the requirements for the reduction of consumer and industrial waste that negatively impacts the development of human civilization were identified. A detailed analysis of current trends in green energy and climate change was carried out by Zhiltsov et al. (2020). Based on the research, it is proposed to form a potential scenario for the development of the world energy balance. Based on the forecasts, it is possible to determine the global increase in energy consumption in the world. If in 2000 the total energy consumption was 9.9 million tons oil equivalent, in 2030 this indicator will reach 20 million tons oil equivalent, and the forecast for 2050 is around 32 million tons oil equivalent. By approximately 2050, the percentage of green energy should exceed $30 \%$ of the global energy balance, with gas in second place as the main energy source. However, even this situation will lead to an increase in the use of traditional energy sources, which threatens the stability of ecosystems and the quality of life of future generations.

It is worth noting that the use of waste from consumption and production to obtain energy resources is accompanied by innovative transformations, and therefore provides a 
high level of innovative potential. Without the use of innovative technologies, it is impossible to reduce the negative impact on the environment and limit the use of hydrocarbons in economic practice. Innovations in alternative energy will also have a synergistic effect on other industries and territorial development, taking into account the social orientation of economic relations (Elfani, 2011; Detemple and Kitapbayev, 2020).

\subsection{Conceptual Provisions of the Circular Economy}

The achievement of sustainable development has the basic goal of ensuring the prosperity of human civilization, and the implementation of its principles in practice requires the creation of an enabling environment. Such favorable conditions include the formation of an appropriate level of innovation (primarily through knowledge management), the spread of digitalization, and intellectualization (as stated in, e.g., Matos et al., 2018; Balashova and Sharipova, 2019; Mikalauskiene and Atkociuniene, 2019). Many studies have noted that the economies of the most technologically advanced countries actively use intellectual resources for intensive development, which helps to reduce costs and increase productivity. Global corporations dictate the trends of the time, which currently include the transformation of the ecological and economic space. Thus, at the business level, the diffusion of knowledge and its transformation into intellectual resources enables achieving competitive advantages and implementing new directions, methods, and ways to achieve sustainable development. One of these areas is the circular economy.

The fundamental aspects of the circular economy in the context of sustainable development were discussed in the work of Scott (2013). The objectives of the circular economy are aimed at minimizing the waste of human life and the production and economic activities of economic entities at all levels. The significance of these areas was considered in the work of Boulding (1966) back in the 1960s, where some aspects of the creation of waste-free production and its economic justification were already noted. At the moment, we can talk about the circular economy as a new paradigm, the trends of which will further strengthen in influence on the macroeconomic space. The practical implementation of the conceptual provisions of the circular economy in the scientific community has already been sufficiently developed; however, the developed concepts have not been sufficiently strengthened in practice in industry and energy policy (Geissdoerfer et al., 2017).

As an alternative to the linear economic model, in the circular economy it is possible to restore and regenerate material resources in the process of conceptualizing the integration of economic activity and environmental well-being in order to achieve the key goals of sustainable development. Circular models are aimed at solving a number of global problems, since they can become a stimulator of ecological configuration in production (Masi et al., 2017). However, businesses are often not interested in their implementation, because despite the high importance of circular models both at the state and at the business levels, there are problematic situations for conducting economic calculations and justifying the development of circular elements from an innovative position in the current economic system.

\subsection{The Place of Alternative Energy in Circular Models}

Circular models as an alternative to traditional linear models are based on the renewal of resources and striving for maximum recycling of waste. In the context of energy, circular models focus on the use of waste to generate an energy resource. Multiple recycles contribute to increasing waste-free and minimizing the pollution that is characteristic of the energy sector. The development of alternative energy also reduces the use of fossil minerals. An example of such a direction is the use of industrial waste to produce heat, electricity, and bioenergy. These sources are an integral part of alternative energy and can 
reduce the use of traditional types of energy, leaving the maximum amount of resources in the economic cycle.

Based on the analyzed studies, it can be concluded that in the business environment it is necessary to form tools for the development of the innovative potential of energy enterprises. The state of innovation potential determines the ability to implement technological innovations by increasing investment attractiveness. The lack of reasonable consistency of the principles of the circular economy with the investment and innovation aspects of alternative energy hinders the development of a modern apparatus for ensuring an accelerated transition away from the consumer characteristics of traditional linear production (Kirchherr et al., 2017; Bressanelli et al., 2019). The scientific community does not currently have a universal approach for assessing the innovative potential of energy enterprises that would take into account the peculiarities of their functioning in alternative energy, which opens up opportunities for the development of this topic while taking into consideration the requirements of modernity.

Conducting a comprehensive analysis of the current state of the study problem allows us to form a methodology for determining the innovative potential of alternative energy. However, the lack of scientific and practical knowledge in this area does not allow us to increase the efficiency of intensive ways of economic development and ensure the inflow of intellectual super-profits. Additional income from the operation of enterprises due to the implementation of their innovative potential will provide a strong competitive advantage in the market environment. Intellectual rent is already stimulating changes in the structure of rental income in the economy (Zaytsev et al., 2021), and is also recognized as an indicator of business success and ensures the dominance of the most technologically advanced countries and multinational corporations in the macroeconomic space. Alternative energy is no exception, since the dominance of such a high-tech industry is impossible to imagine without large-scale intellectualization and an increase in intangible consumption (Dmitriev et al., 2020; Gorovoy et al., 2020; Ilchenko et al., 2020).

The enterprise management level was selected as the space in which to adapt the authors' idea, since it is at this level that the greatest innovative activity which can affect the diffusion of "circular" innovations is manifested. The innovative and digital dynamics of the economic space allow us to use circular models to identify the factors that determine the development of alternative energy. The structural place of the innovative potential of alternative energy in the system of resource interaction is shown in Figure 1.

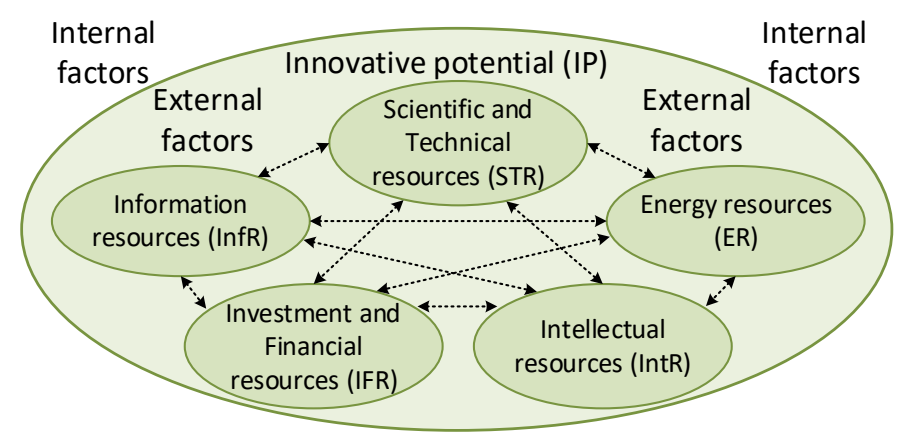

Figure 1 The structural place of the innovative potential of alternative energy in the system of resource interaction

Thus, the innovation potential is formed under the influence of resource elements: $I P=$ $\{S T R ; E R ; I n t R ; I F R ; I n f R\}$. The indicator of the impact of these resources can be calculated on the basis of economic and mathematical methods, but for the introduction of an 
integrated indicator of innovation potential the authors propose forming an apparatus for assessing the innovative potential of alternative energy enterprises. The obtained value can be compared with the cost indicators and the level of circular production. In this system, it is necessary to take into account a number of determinants, which can be divided into internal and external factors. At the same time, the factors are interrelated, and if favorable conditions are created for their synergistic impact, it becomes possible to use the innovative potential with increased efficiency. The end result of this process is to increase the competitiveness of the alternative energy entity by achieving excess efficiency indicators. The authors propose identifying the following factors:

1. For the external environment: the current state policy in the sustainable development field; market openness for external investors; legislative regulation of the energy sector; state support for alternative energy; mechanisms of public-private partnership in the innovative segment of energy; conditions created by the state to enable the access of alternative energy enterprises to the necessary resources; industry specifics of the application of new technological solutions in the energy sector; and the development of the system of transfer of innovative technologies between the enterprises of alternative energy.

2. For the internal environment: the qualifications of personnel and production workers; the technical condition of fixed assets; the brand and image of the company; the state of the investment attractiveness of the enterprise; sources of financing for innovation; the availability of a comprehensive quality system; the maintenance of environmental safety; information support for innovation; and integration and economic relations with entities.

The proposed list of indicators is schematically shown in Figure 2.

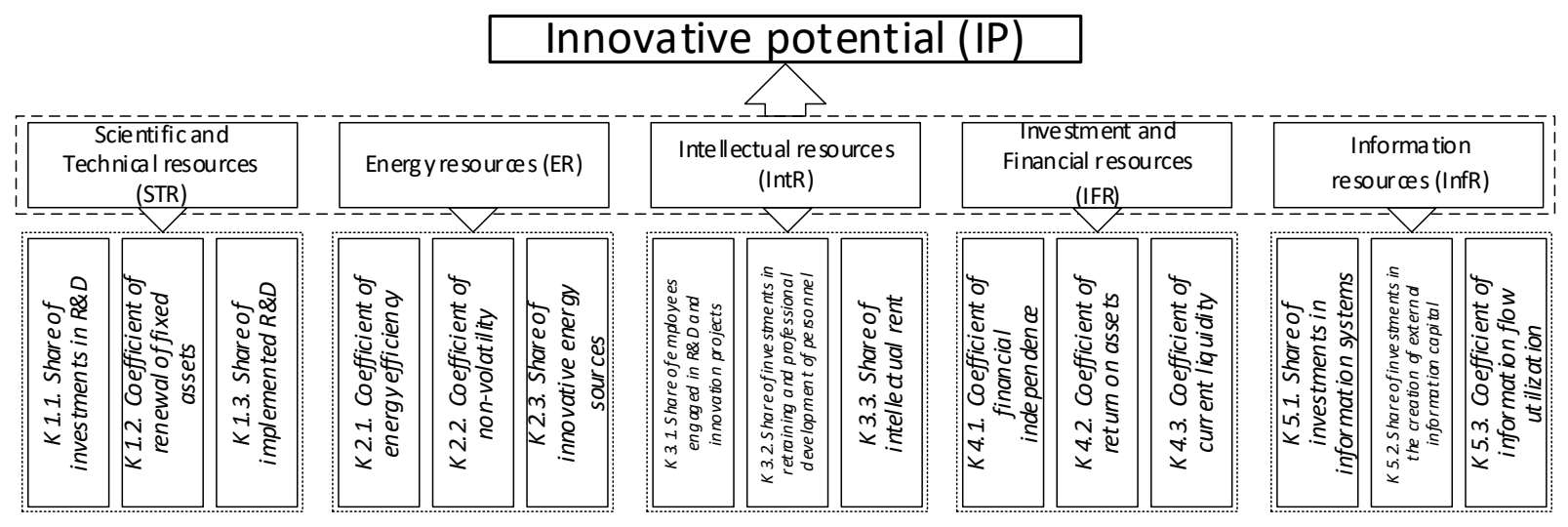

Figure 2 The system of indicators for the integrated assessment of innovation potential

To assess the innovative potential of alternative energy at the level of an economic entity, it is necessary to calculate the value of the integral model, which will set the parameters of innovation (resource elements of innovation potential). It is advisable to consider a set of indicators based on their weight coefficients, reflecting the significance of a particular indicator (from 0 to 100 points). Thus, the innovation potential indicator should be calculated using Equation 1:

$$
I P=a_{1} \text { STR }+a_{2} \text { ER }+a_{3} \text { IntR }+a_{4} \text { IFR }+a_{5} \text { InfR, }
$$

IP - innovation potential; $\mathrm{a}_{\mathrm{i}}$ - weight coefficient; STR, ER, IntR, IFR, InfR - resource elements.

The weight of each indicator can be changed depending on the country or specific region, as well as on the time dynamics. In the future, it is planned to build models to 
identify standardized indicators for specific regions. The coefficients of each resource direction are calculated directly on the basis of the weight or the number of indicators considered. In this study, each resource element is calculated based on the number of coefficients ( 3 coefficients); therefore, the summed value of each coefficient is divided by 3 . The final value will be in a range from 0 to 100 points, but to determine the level of innovation potential, its level and class can be set by entering specified intervals. Table 1 shows the interval values for determining the level of innovation potential.

Table 1 Interval values of the level of innovation potential

\begin{tabular}{ccl}
\hline Interval & Level & \\
\hline $76-100$ & High & $\begin{array}{l}\text { The entity develops almost only in intensive ways; there is opportunity for large-scale } \\
\text { expansion of energy systems and implementation of technological expansion. } \\
\text { The entity works at an efficient level; innovative technologies develop, and the use of } \\
\text { alternative systems increases, though there is opportunity for further intensive growth. } \\
\text { The entity has innovative developments and sufficient resources, but the effectiveness is } \\
\text { insufficient to ensure sustainable development in the long term. } \\
\text { The entity works at an inefficient level, innovations in economic activity are practically } \\
\text { not used, and the development of alternative energy at this level is almost impossible. }\end{array}$ \\
\hline
\end{tabular}

\section{Results}

To confirm the effectiveness of the authors' methodology, it was tested at enterprises that implement measures for processing production and consumption waste into an energy resource. The innovative nature of the activity and the focus of economic entities on minimizing the negative impact on the environment were taken into account. This study considers the results for 10 enterprises that carry out activities in the field of alternative energy. These enterprises operate on the Russian market and implement complex investment projects aimed at obtaining alternative energy by recycling waste. At the same time, data on these enterprises are available in the public domain, which facilitated the research. The developed assessment methodology provides an opportunity to consider the change in the obtained indicators for a certain period. For the analyzed enterprises, data are available from 2015 to 2019 . The calculated indicators of innovation activity are shown in Figure 3. Based on the authors' analysis, it was determined that after 2015, a sharp rise in the level of innovation potential among the enterprises under consideration was observed, which was largely due to the mass popularization of the circular direction in world trends. While the average indicator of innovation potential in 2015 was 51.9 points, in 2019 it had already reached 69.1 points (2016 - 64.8 points; 2017 - 63.6 points; 2018 68 points). This trend indicates the significant innovative potential of alternative energy and favorable prospects for its further development in the context of the transition to the circular economy.

Based on this indicator, it is possible to quickly respond to potential threats by identifying weaknesses in the resource areas of the integrated model of innovative potential. The innovation potential of the analyzed enterprises was at an acceptable level throughout the entire period and continues to grow, which makes it possible to build strategic guidelines for development in this area. However, it is advisable to compare the obtained indicators with the level of circular production in dynamics. The study focuses on the circular model of energy efficiency of enterprises, that is, on determining the key values of waste processing into an energy resource. The calculated dynamics are shown for the enterprises in Figure 4. While in 2015, on average, only 55.9\% of waste was processed into an energy resource, by 2019 the average value had already reached 77.5\% (2016-65.2\%; $2017-68.6 \% ; 2018-72.2 \%$ ). Evidently, there has been a sharp increase in the recycling of 
waste into an energy resource, which corresponds to the interests of the circular economic system and the principles of sustainable development.

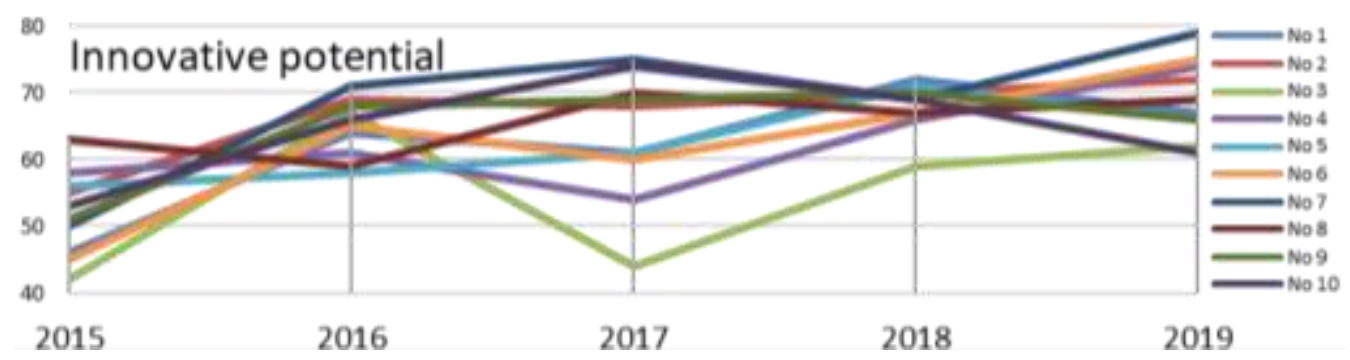

Figure 3 The dynamics of the innovative potential of alternative energy enterprises

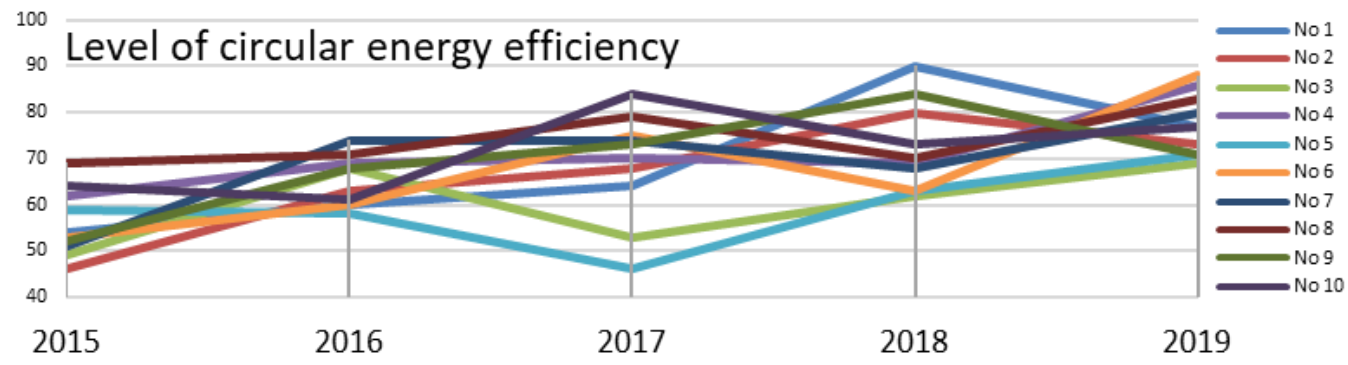

Figure 4 The level of circular energy efficiency of the analyzed enterprises

On the basis of the obtained data, a correlation analysis for enterprises and a two-factor regression were performed to determine the coefficient of determination ( $Y$ - innovation potential; X - circular energy efficiency). Of the 10 enterprises analyzed, only two had a weak dependence between innovation potential and circular energy efficiency. However, this error can be attributed to the lack of a longer time interval for constructing an extended model. It is safe to say that the intensity of the use of innovative potential in alternative energy should be understood as an innovative activity that can be directed toward the implementation of circular economy programs.

\section{Discussion}

It is important to note the high importance of obtaining "hybrid" effects from the implementation of innovative potential that affect the growth of cost indicators. Innovation value is the most acceptable indicator, which is manifested in the conditions of achieving a high level of intellectualization of the entity in combination with a systematic increase in the investment attractiveness and image of the business. On the basis of innovation activity, it is possible to regulate the cost characteristics of many enterprises, including in the field of alternative energy (Zaytsev et al., 2020; Woodhead and Berawi, 2020). In current conditions, there are new opportunities for expanding the use of business models and obtaining effects from interactions with public structures. The innovation potential and positive effects of alternative energy can be influenced not only by direct participants in the internal business process, but also by external structures through information influence. Therefore, we cannot limit ourselves only to the social effects of circular production and the economic significance of the growth of innovation potential, but should consider a number of positive effects for all stakeholders. At the same time, the interests of stakeholders should be combined in the following areas: investment activity, support for development, level of well-being, information security, ensuring profitability, energy supply, and sustainable development. 


\section{Conclusions}

As a result of this research, a comprehensive analysis of alternative energy in the context of the transition to the circular economy was carried out, which allowed us to develop the theoretical and practical material of the concept of the circular economy, which is currently actively popularized in the scientific and practical environment. In considering the main areas of research regarding this issue, the authors determined the current state of alternative energy and its prospects for development, worked out the issues of the circular economy and the possibility of its acceleration, and also reflected on the place of alternative energy sources in circular models, which opens the way for expanded research in this field. Based on the analysis of the perspectives in the scientific community, a methodology, the essence of which comprised building an integrated model that allows to assess the innovative potential of alternative energy at the level of an economic entity, was proposed. The innovative potential of enterprises allows us to talk about the development of "clean" ways of obtaining energy resources. It has been proven that such a practice is in the interests of society and the state, since it can solve not only regional problems, but also threatening externalities on a global scale.

\section{Acknowledgements}

The research is partially funded by the Ministry of Science and Higher Education of the Russian Federation under the strategic academic leadership program 'Priority 2030' (Agreement 075-15-2021-1333 dated 30.09.2021).

\section{References}

Azzopardi, B., 2017. Sustainable Development in Energy Systems. Sustainable Development in Energy Systems. Springer, Cham, Switzerland

Balashova, E., Sharipova, S., 2019. The Role of Big Data in the Sustainable Business Strategy. In: Proceedings of the 33 ${ }^{\text {rd }}$ IBIMA Conference. Granada, Spain, pp. 8839-8844

Bataev, A.V., 2018. Analysis and Development the Digital Economy in The World. In: Proceedings of the $31^{\text {st }}$ IBIMA Conference. Milan, Italy, pp. 61-71

Bermejo, R., 2014. Handbook for a Sustainable Economy. Handbook for a Sustainable Economy. Springer Science, New York, USA

Bhattacharyya, S.C., 2019. Energy Economics: Concepts, Issues, Markets and Governance. Springer, UK

Boulding, K.E., 1966. The Economics of Knowledge and the Knowledge of Economics. The American Economic Review, Volume 56(1/2), pp. 1-13

Bressanelli, G., Perona, M., Saccani, N., 2019. Challenges In Supply Chain Redesign for the Circular Economy: A Literature Review and a Multiple Case Study. International Journal of Production Research, Volume 57(23), pp. 7395-7422

Chen, S., 2020. What Implications does COVID-19 have on Sustainable Economic Development in the Medium and Long Terms? Frontiers of Economics in China, Volume 15(3), pp. 380-395

Chernysheva, N.A., Perskaya, V.V., Petrov, A.M., Bakulina, A.A., 2019. Green Energy for Belt and Road Initiative: Economic Aspects Today and in the Future. International Journal of Energy Economics and Policy, Volume 9(5), pp. 178-185

Common, M., Stagl, S., 2005. Ecological Economics: An introduction. Ecological Economics: An Introduction. Cambridge University Press, Cambridge, UK

Detemple, J., Kitapbayev, Y., 2020. The Value of Green Energy Under Regulation Uncertainty. Energy Economics, Volume 89(2), https://doi.org/10.1016/j.eneco.2020.104807 
Dmitriev, N., Zaytsev, A., Dubanevich, L., 2020. Determining the Strategic Prospects of an Enterprise by Assessing the Dynamics of its Intellectual Rent. Montenegrin Journal of Economics, Volume 16(4), pp. 187-197

Doukas, H., Flamos, A., Lieu, J., 2018. Understanding Risks and Uncertainties in Energy and Climate Policy: Multidisciplinary Methods and Tools for a Low Carbon Society. Springer, Cham

Elder-Vass, D., 2016. Profit and Gift in the Digital Economy. University Press, Cambridge, UK Elfani, M., 2011. The Impact of Renewable Energy on Employment in Indonesia. International Journal of Technology, Volume 2(1), pp. 47-55

Geissdoerfer, M., Savaget, P., Bocken, N., Hultink, E., 2017. The Circular Economy - A New Sustainability Paradigm? Journal of Cleaner Production, Volume 143, pp. 757-768

Gorovoy, A., Dmitriev, N., Zaytsev, A., 2020. Development of the Methodology for Calculating the Intellectual Rent of an Industrial Enterprise. In: Proceedings of the ICICKM. Toronto, Canada, pp. 158-169

Guan, J., Yan, Y., 2016. Technological Proximity and Recombinative Innovation in the Alternative Energy Field. Research Policy, Volume 45(7), pp. 1460-1473

Ilchenko, S., Rodionov, D., Zaytsev, A., Dmitriev, N., 2020. Assessing Intellectual Capital from the Perspective of its Rental Income Performance. International Journal of Technology, Volume 11(8), pp. 1489-1498

Kirchherr, J., Reike, D., Hekkert, M., 2017. Conceptualizing the Circular Economy. Resources, Conservation and Recycling, Volume 127, pp. 221-232

Madureira, N.L., 2014. Key Concepts in Energy. Key Concepts in Energy. Springer, Cham

Mamrayeva, D., Stybaeyeva, A., Tashenova, L., 2018. The Research of Global Innovation Capital. Economic Annals-XXI, Volume 167(9-10), pp. 4-7

Masi, D., Day, S., Godsell, J., 2017. Supply Chain Configurations in the Circular Economy: A Systematic Literature Review. Sustainability, Volume 9(9), pp. 1-22

Matos, F., Vairinhos, V., Selig, P.M., Edvinsson, L., 2018. Intellectual Capital Management as a Driver of Sustainability: Perspectives for Organizations and Society. Springer, Cham

Mikalauskiene, A., Atkociuniene, Z., 2019. Knowledge Management Impact on Sustainable Development. Montenegrin Journal of Economics, Volume 15(4), pp. 149-160

Murray, A., Skene, K., Haynes, K., 2017. The Circular Economy: An Interdisciplinary Exploration of the Concept and Application in a Global Context. Journal of Business Ethics, Volume 3(1), pp. 369-380

Rudskaia, I., Rodionov, D., Degtereva, V., 2017. Assessment of the Effectiveness of Regional Innovation Systems in Russia. In: Proceedings of the 29th IBIMA Conference. pp. 34373449

Sarkodie, S.A., Owusu, P.A., 2020. Impact of COVID-19 Pandemic on Waste Management. Environment, Development and Sustainability, Volume (23), pp. 7951-7960

Schwarz, P.M., 2017. Energy Economics. Energy Economics. Taylor \& Francis, London, UK

Scott, T., 2013. The Sustainable Business: A Practitioner's Guide to Achieving Long-Term Profitability and Competitiveness. $2^{\text {nd }}$ ed. Routledge, London, UK

Soderbaum, P., 2013. Ecological Economics: Political Economics for Social and Environmental Development. Ecological Economics: Political Economics for Social and Environmental Development. Routledge, London, UK

SR15, 2018. Special Report on Global Warming of $1.5^{\circ} \mathrm{C}$. Intergovernmental Panel on Climate Change (IPCC)

SRCCL, 2019. Special Report on Climate Change and Land. Intergovernmental Panel on Climate Change (IPCC) 
Vasetskaya, N., Gaevskaia, T., 2019. Digitalization as an instrument for economic growth. In: Proceedings of the 33 ${ }^{\text {rd }}$ IBIMA Conference. Granada, Spain, pp. 8914-8919

Witjes, S., Lozano, R., 2016. Towards a More Circular Economy: Proposing a Framework Linking Sustainable Public Procurement and Sustainable Business Models. Resources, Conservation and Recycling, Volume 112, pp. 37-44

Woodhead, R., Berawi, M.A., 2020. Value Creation and The Pursuit of Multi Factor Productivity Improvement. International Journal of Technology, Volume 11(1), pp. 111-122

Zaborovskaya, O., Kudryavtseva, T., Zhogova, E., 2019. Examination of Mechanisms of Regional Sustainable Development Strategy as Exemplified by the Leningrad Region. International Journal of Engineering and Advanced Technology, Volume 9(1), pp. 50655076

Zaytsev, A., Rodionov, D., Dmitriev, N., Faisullin, R., 2020. Building a Model for Managing the Market Value of an Industrial Enterprise based on Regulating its Innovation Activity. Academy of Strategic Management Journal, Volume 19(4), pp. 1-13

Zaytsev, A., Talerchik, S., Dmitriev, N., 2021. Evaluating Rental Factors of Innovation Sustainability in Russian Regions using Index Methods. Montenegrin Journal of Economics, Volume 17(2), pp. 93-103

Zhiltsov, S., Dmitriev, N., Zaytsev, A. 2020. Economic Aspects of the Need to Develop Green Energy. Business. Education. Law, Volume 53(4), pp. 63-70 